\title{
Corona Virus Disease among Pregnant Women: A Systematic Scoping Review
}

\author{
Consolata Kirigia \\ Midwifery Lecturer School of Nursing, Department of Midwifery, University of Embu, Embu, Kenya \\ Email: kirigia.consolata@embuni.ac.ke,consolatakirigia@gmail.com
}

How to cite this paper: Kirigia, C. (2020) Corona Virus Disease among Pregnant Women: A Systematic Scoping Review. Open Journal of Obstetrics and Gynecology, 10, 671-677.

https://doi.org/10.4236/ojog.2020.1050060

Received: April 16, 2020

Accepted: May 8, 2020

Published: May 11, 2020

Copyright $\odot 2020$ by author(s) and Scientific Research Publishing Inc. This work is licensed under the Creative Commons Attribution International License (CC BY 4.0).

http://creativecommons.org/licenses/by/4.0/

\section{(c) (i) Open Access}

\begin{abstract}
Corona Virus Disease 2019 (COVID-19) is a deadly respiratory viral disease that started in China in the year 2019 before spreading to the world. It affects everybody regardless of race, religion, social economic status or age. However, literature indicates that people with compromised immune status are at a higher risk of contracting viral infections. During pregnancy, the immune status of the woman is suppressed because it acts to protect both the mother and her unborn baby. The purpose of this study was to provide an overview of available evidence on the risk of contracting COVID-19 and COVID-19 infection prevention among pregnant women. Relevant and recent articles were identified from various databases. Article selection was aligned to the study questions. Articles that were related to study objectives were included and those not related to study objectives were excluded. A narrative report was produced and results were described according to study objectives. Approximately 8 data sources were included and most of the reviewed articles indicated that pregnant women are at a higher risk of getting COVID-19. The reviews further indicated that pregnant women can be prevented from this deadly virus by providing community antenatal services instead of visiting the health facilities. If a pregnant woman develops symptoms of respiratory infection, it is advisable to seek immediate diagnosis to rule out COVID-19 and get appropriate management to avoid complications. The selected studies' quality was appraised through Mixed Methods Appraisal Tool (MMAT) version 2018. Knowledge on the risk of COVID-19 infection among pregnant women will help health workers especially midwives who take care of pregnant women to design confidently and put into action preventive programs to address health needs of pregnant women who are at a higher risk of contracting COVID-19 as compared to other people in the general population. This also will assist health workers to provide appropriate care to pregnant women on the basis of their COVID-19 infection risk status at health facility and community levels. This study review is also creating more awareness on
\end{abstract}


the risk of COVID-19 to pregnant women even in communities. It serves as evidence to guide health policymakers to put emphasis on addressing the preventive measure of this greatly vulnerable group of population. To prevent COVID-19 infection during pregnancy, pregnant women should strictly follow the laid down measures of prevention by World Health Organisation (WHO) and their local health authorities.

\section{Keywords}

Corona Virus, Risk of COVID-19, Pregnant Women, Pregnancy, Infection Prevention

\section{Background}

Corona Virus Disease (COVID-19) affects everybody regardless of race, religion, social economic status or age [1]. However people with compromised immune status are at a higher risk of contracting viral infections including corona virus [2]. During pregnancy, the immune status of the woman is suppressed because it acts to protect both the mother and her unborn baby. All body systems are affected during pregnancy including the endocrine system where hormonal levels become abnormal and this makes the woman more vulnerable to the infection compared to others in the general population and this can result in severe complications [3]. Due to low immunity during pregnancy, pregnant women are at a higher risk of contracting the corona virus [2]. When the health of a mother is poor, it poses a risk to wellbeing of the unborn child and can sometimes lead to miscarriage [4]. Prevention of the disease is therefore paramount because drugs that will be used in treatment put the pregnancy even in a worse situation as most drugs are contraindicated in pregnancy [2]. If a pregnant woman develops symptoms of respiratory infection, it is advisable to seek immediate diagnosis to rule out COVID-19 and get appropriate management to avoid complications [2]. To prevent COVID-19 infection during pregnancy, pregnant women should strictly follow the laid down measures of prevention. These include regular hand washing for 20 seconds with soap under running water, sanitisation with at least $70 \%$ alcohol-based sanitiser, avoid touching eyes, nose, mouth, social distancing and staying at home [5] [6]. According to European Centre for Disease Prevention and Control, pregnant women are not more at risk of contracting COVID-19 or suffering from the more severe disease than other adults of similar age. Therefore pregnant women are advised to take preventive measures like: If they become ill with symptoms of cough, fever and difficulty breathing to stay home and call their local health care services for advice. Mention that they are pregnant. If they are found ill with COVID-19: To call their midwife or antenatal care provider and inform them about the illness. Request instructions on how to proceed with antenatal care appointments and delivery plans during the course of illness. The purpose of this study was to provide an overview of available evi- 
dence on the risks of contracting COVID-19 and COVID-19 infection prevention strategies among pregnant women. According to World Health Organisation [7] [8], there is no evidence that pregnant women present with increased risk of severe illness or fetal compromise [9]. Pregnant and recently pregnant women who have recovered from COVID-19 should be enabled and encouraged to attend routine antenatal, postpartum or post-abortion care as appropriate. Additional care should be provided if there are any complications.

\section{Objective}

1) To provide an overview of available evidence on the risks of contracting COVID-19 among pregnant women.

2) To provide an overview of available evidence on COVID infection prevention among pregnant women.

\section{Question}

1) Is there evidence that pregnant women are at a higher risk of contracting COVID-19 among the general population?

2) What is the available evidence on the preventive measures to prevent COVID-19 infection among pregnant women?

\section{Methodology}

This is a review of reported literature following Arksey and O'Malley's framework and preferred reporting items for scoping reviews checklist in reporting the study results.

\section{Information sources and search strategy}

Relevant and recent articles not older than five years from 2016-2020 were identified from various databases such as PubMed, HINARI, Google Scholar, $\mathrm{BMC}$ and Cochrane. Key search words used were Corona virus, Risk of COVID-19, pregnant women, pregnancy, and infection prevention. More relevant studies were retrieved by searching references from the articles that were included from different websites like International Confederation of Midwives (ICM), World Health Organization (WHO).

\section{Selection of eligible studies}

Article selection was aligned to the study questions. For articles to be considered for review, they must have had included keywords from research objectives such as Corona Virus Disease among Pregnant Women, risk of contracting COVID-19 among pregnant women or COVID prevention among pregnant women. Only articles published in credible journals were included, also they must have been written in English language. Studies done by mixed-methods were preferred so as to consider various aspects of determining risks of contracting COVID-19 among pregnant women or COVID prevention among pregnant women. Articles which didn't fit into the study conceptual framework were excluded. Around 108 articles were retrieved, of which 100 were excluded depending on study title, objectives, study questions and keywords. Twenty 
three articles were further identified for text review and 15 were excluded based on their different outcomes and type of language used other than English. Therefore 8 articles were identified and included for this review.

\section{Inclusion criteria}

Articles that studied issues concerning or related to Corona Virus Disease among Pregnant Women, risks of contracting COVID-19 among pregnant women or COVID prevention among pregnant women were included in this study. Only those articles written in English and published in credible peer reviewed journal were included (Table 1).

\section{Exclusion criteria}

Articles that were not about the study of Corona Virus Disease among Pregnant Women, risks of contracting COVID-19 among pregnant women or COVID prevention among pregnant women were excluded in this study. Those articles written in other languages apart from English and those not peer reviewed were excluded.

\section{Data extraction method}

The information that contributed to answering the research questions was charted. Details of publication information were recorded along with this information. The information extracted that helped answer the research questions were revised thoroughly in order to work towards an overall perspective on the factors emerging from the literature (Table 1).

\section{Charting the data}

Relevant information that was included involved such information as study design, year in which the journal was published, sample size and study settings, objective and any other information that was important in capturing relevant

Table 1. Characteristics of included articles.

\begin{tabular}{|c|c|c|c|c|}
\hline First Author & Publication year & Title/Keywords & Inclusion criteria & Study Population and Results \\
\hline Khan S. et al. & 2020 & $\begin{array}{l}\text { Association of COVID-19 with } \\
\text { pregnancy outcomes in health-care } \\
\text { workers and general women }\end{array}$ & $\begin{array}{l}\text { Relevant to this review objectives, } \\
\text { Recent, English language, Credible }\end{array}$ & $\begin{array}{l}\text { Pregnant Health care providers at } \\
\text { risk of COVID-19 than } \\
\text { General women }\end{array}$ \\
\hline Della Gatta et al. & 2020 & COVID19 during pregnancy & $\begin{array}{l}\text { Relevant to this review objectives, } \\
\text { Recent, English language, Credible }\end{array}$ & $\begin{array}{l}\text { Pregnant women at risk of } \\
\text { COVID-19 }\end{array}$ \\
\hline $\begin{array}{l}\text { Vincenzo } \\
\text { Berghella }\end{array}$ & 2020 & $\begin{array}{l}\text { Corona virus disease } 2019 \\
\text { (COVID-19): Pregnancy issues }\end{array}$ & $\begin{array}{l}\text { Relevant to this review objectives, } \\
\text { Recent, English language, Credible }\end{array}$ & $\begin{array}{l}\text { Pregnant women at risk of } \\
\text { COVID-19 }\end{array}$ \\
\hline Nina Bai & 2020 & $\begin{array}{l}\text { What We Know and Don't Know } \\
\text { About Corona virus and Pregnancy }\end{array}$ & $\begin{array}{l}\text { Relevant to this review objectives, } \\
\text { Recent, English language, Credible }\end{array}$ & $\begin{array}{l}\text { Pregnant women at risk of } \\
\text { COVID-19 }\end{array}$ \\
\hline Morris E & 2020 & $\begin{array}{l}\text { Corona virus (COVID-19) infection } \\
\text { and pregnancy }\end{array}$ & $\begin{array}{l}\text { Relevant to this review objectives, } \\
\text { Recent, English language, Credible }\end{array}$ & $\begin{array}{l}\text { Pregnant women at risk of } \\
\text { COVID-19 }\end{array}$ \\
\hline Yongwen Luo & 2020 & $\begin{array}{l}\text { Management of pregnant women } \\
\text { infected with COVID-19 }\end{array}$ & $\begin{array}{l}\text { Relevant to this review objectives, } \\
\text { Recent, English language, Credible }\end{array}$ & $\begin{array}{l}\text { Pregnant women at risk of } \\
\text { COVID-19 }\end{array}$ \\
\hline CDC, Morris et al. & 2020 & $\begin{array}{l}\text { Information on COVID-19 for } \\
\text { pregnant women }\end{array}$ & $\begin{array}{l}\text { Relevant to this review objectives, } \\
\text { Recent, English language, Credible }\end{array}$ & $\begin{array}{l}\text { Pregnant women can be } \\
\text { prevented from COVID-19 same } \\
\text { way as general population }\end{array}$ \\
\hline
\end{tabular}


data to the validity of the study. Important characteristics of participants like age and gender were also included and interventions like COVID-19 preventive measures and findings which were keys to the research objectives.

\section{Results Report}

A narrative report was produced that summarized data which were extracted from the region in which the study was done. An account on risk of contracting COVID-19 among pregnant women and COVID prevention among pregnant women was availed from the extracted data. The study findings were described according to the study objectives. Approximately 8 data sources were included. Most of the reviewed articles indicated that pregnant women are at a higher risk of getting COVID-19 [10]. The reviews further indicated that pregnant women can be prevented from this deadly virus by reorganizing strategies of service provision to pregnant mothers in the community instead of visiting health facilities. In a conversation by creative commons, pregnant women are at a higher risk of getting COVID-19 due to low immunity, and symptoms will be more severe if the woman is in her last trimester [11]. Pregnant women are more likely to experience severe illness if affected by the Corona Virus [12]. COVID-19 was associated with respiratory insufficiency in late pregnancy [13]. Being a health care provider and pregnant, poses one to risk of COVID-19 related pregnancy complications than the general women [14]. According to European Centre for Disease Prevention and Control, pregnant women are not more at risk of contracting COVID-19 or suffering from the more severe disease than other adults of similar age. Therefore pregnant women are advised to take preventive measures like: If they become ill with symptoms of cough, fever and difficulty breathing to stay home and call their local health care services for advice. Mention that they are pregnant. If they are found ill with COVID-19: To call their midwife or antenatal care provider and inform them about the illness. Request instructions on how to proceed with antenatal care appointments and delivery plans during the course of illness. Pregnant women can be prevented from risk of COVO-19 by increasing number of home births and reducing hospital births [15]. The same measures taken by general population can be taken by pregnant women to protect themselves from COVID-19 [12] [16]. According to what is known about pregnancy and other respiratory infections, pregnant women are at a higher risk of contracting COVID-19 [17]. Health workers who are pregnant are advised not to work face to face on patients who are diagnosed with COVID-19 during their third trimester as from 36 weeks to reduce chances of contracting the virus [18].

\section{Quality appraisal}

The selected studies quality was appraised through Mixed Methods Appraisal Tool (MMAT) version 2018.

\section{Discussion}

This review aimed at determining the risks of contracting COVID-19 among 
pregnant women and COVID prevention among pregnant women. This study review forms the initial part of future studies that may be interested in developing guidelines on prevention strategies towards COVID-19 infection among pregnant women especially in low resource settings. Knowledge on the risks of COVID-19 infection among pregnant women will help health workers especially midwives who take care of pregnant women to design confidently and put into action preventive programs to address health needs of pregnant women who are at a higher risk of contracting COVID-19 as compared to other people in the general population. This also will assist health workers to provide appropriate care to pregnant women on the basis of their COVID-19 infection risk status at health facility and community levels. This study review is also creating more awareness on the risks of COVID-19 to pregnant women even in communities. It serves as evidence to guide health policymakers to put emphasis on addressing the preventive measure of this greatly vulnerable group of population. Most of the reviewed articles indicated that pregnant women are at a higher risk of getting COVID-19 [2]. This is because of their compromised immunological process [19]: The reviews further indicated that pregnant women can be prevented from this deadly virus by reorganizing strategies of providing community antenatal services instead of women visiting the health care facilities [5].

\section{Funding}

There was no relevant financial relationship to this review.

\section{Conflicts of Interest}

The author declares no conflicts of interest regarding the publication of this paper.

\section{References}

[1] WHO (2020) Corona Viruses (COVID-19). https://www.who.int/emergencies/diseases/novel-coronavirus-2019

[2] Khan, M.A., et al. (2020) COVID-19 Infection during Pregnancy: A Systematic Review to Summarize Possible Symptoms, Treatments, and Pregnancy Outcomes. BMJ. https://doi.org/10.1101/2020.03.31.20049304

[3] Cherney, K., Sallis, D. and Digmann, J. (2016) Infections in Pregnancy. Parenthood.

[4] Lam, C.M., Wong, S.F., Leung, T.N., et al. (2016) A Case-Controlled Study Comparing Clinical Course and Outcomes of Pregnant and Non-Pregnant Women with Severe Acute Respiratory Syndrome. BJOG, 111, 771-774. https://doi.org/10.1111/j.1471-0528.2004.00199.x

[5] RCM/RCOG (2020) Guidance for Antenatal and Postnatal Services during the Evolving Corona Virus (COVID-19) Pandemic. https://www.rcog.org.uk/en/guidelines-researchservices/guidelines/coronaviruspreg $\underline{\text { nancy }}$

[6] WHO (2020) Coronavirus Disease (COVID-19) Advice for the Public. https://www.who.int/emergencies/diseases/novel-coronavirus-2019/advice-for-public

[7] WHO (2020) Q \& A on COVID-19, Pregnancy, Childbirth and Breastfeeding. 
[8] WHO (2020) Clinical Management of Severe Acute Respiratory Infection (SARI) When COVID-19 Disease Is Suspected. Interim Guidance.

[9] Liu, D., et al. (2020) Pregnancy and Perinatal Outcomes of Women with Corona Virus Disease (COVID-19) Pneumonia: A Preliminary Analysis. AJR. American Journal of Roentgenology, 1-6. https://doi.org/10.2214/AJR.20.23072

[10] Luo, Y.W. and Yin, K. (2020) Management of Pregnant Women Infected with COVID-19. The Lancet, 20, 513-514. https://doi.org/10.1016/S1473-3099(20)30191-2

[11] Zaigham, M. and Andersson, O. (2020) Coronavirus, Pregnant Women and Infants-New Research. The Conversation.

[12] Morris, E., O’Brien, P., Goodyear, G., Relph, S., Jardine, J., Powell, A., Gilgunn-Jones, E., Mullins, E., Viner, R., Evans, D. and Ross-Davie, M. (2020) Corona Virus (COVID-19) Infection and Pregnancy. Information for Healthcare Professionals Version 7: RCOG \& RCM.

[13] Della Gatta, A.N., Rizzo, R., Pilu, G. and Simonazzi, G (2020) COVID19 during Pregnancy: A Systematic Review of Reported Cases. American Journal of Obstetrics \& Gynecology. https://doi.org/10.1016/j.ajog.2020.04.013

[14] Khan, S., et al. (2020) Association of COVID-19 with Pregnancy Outcomes in Health-Care Workers and General Women. Clinical Microbiology and Infection. https://doi.org/10.1016/j.cmi.2020.03.034

[15] Birthplace in England Collaborative Group (2016) Perinatal and Maternal Outcomes by Planned Place of Birth for Healthy Women with Low-Risk Pregnancies: The Birthplace in England National Prospective Cohort Study. BMJ, 343, d7400.

[16] European Centre for Disease Prevention and Control (2020) Information on COVID-19 for Pregnant Women.

[17] Bai, N.N. (2020) What We Know and Don't Know about Coronavirus and Pregnancy: Enrolling Pregnant Women for Nationwide Study about COVID-19. Center for Disease Control, California.

[18] Berghella, V. (2020) Corona Virus Disease 2019 (COVID-19): Pregnancy Issues.

[19] Liu, H., et al. (2020) Why Are Pregnant Women Susceptible to Viral Infection: An Immunological Viewpoint? Journal of Reproductive Immunology, 139, Article ID: 103122. https://doi.org/10.1016/j.jri.2020.103122

\section{Abbreviations}

COVID-19: Corona Virus Disease 2019

MMAT: Mixed Methods Appraisal Tool

WHO: World Health Organisation

RCM: Royal College of Midwives

RCOG: Royal College of Obstetricians and Gynaecologists 